Original article

\title{
Does fear for infection affect condom use and HIV testing? A study of female sex workers in Pune city
}

\author{
Manisha Gore ${ }^{\mathrm{a}, *}$, Prakash Narayanan ${ }^{\mathrm{b}, \mathrm{d}}$, Sanjay Juvekar ${ }^{\mathrm{c}}$ \\ ${ }^{a}$ Symbiosis Institute of Health Sciences, Symbiosis International (Deemed) University, Lavale, Mulshi, Pune, Maharashtra, 412115, India \\ ${ }^{\mathrm{b}}$ Prassana School of Public Health, Manipal Academy of Higher Education, Tiger Circle Road, Madhav Nagar, Manipal, Karnataka, 576104, India \\ ${ }^{\mathrm{c}}$ Head of the Department, Vadu Health and Demographic Surveillance System (Vadu HDSS), Vadu Rural Health Program (VRHP), KEM Hospital Research Center Pune, \\ India \\ ${ }^{\mathrm{d}}$ Department of Health Policy, Prasanna School of Public Health, Manipal Academy of Higher Education, Manipal, India
}

A R T I C L E I N F O

\section{Keywords:}

Brothel based

Female sex workers

Risk perception

HIV testing

\section{Introduction}

Health Belief Model, a health behavior change model identified risk perception as one of the important constructs of public health interventions. ${ }^{1}$ It is an individual's perceived susceptibility to a threat, often found to be assessed in the context of HIV prevention programs. ${ }^{1,2}$ The model elucidates that perception of risk to illness and understanding the significance of prevention should translates to positive health behavior. $^{3}$ HIV interventions emphasize awareness about modes of transmission and correct assessment of risk as to the key elements in adopting safe sex practices. ${ }^{4}$ Worldwide studies in various cultures in diverse communities proved that low-risk perception was influenced by low knowledge about HIV, sex at young age, multiple sexual partners, no or low condom use. ${ }^{1}$ Unfortunately, there is scarce evidence around these associations in the Indian context.

Globally, female sex workers (FSWs), are targeted with interventions promoting knowledge about HIV, consistent condom use, screening and treatment of STI/HIV to ensure sustained safe sex behavior. ${ }^{5}$ In India, long term interventions in FSWs still reflects a prevalence of $7.4 \%$ and above $18 \%$ in Maharashtra and in the red light area of Pune city i.e. study area respectively, as compared to the national percentage of $2.2 \%{ }^{6,7}$ The figures are a concern with the policymakers. At this background, it is essential to understand the pathways of risk perception influencing condom use and HIV testing in this specific population, ${ }^{9,10}$ besides the role of knowledge in transferring the perception to action. ${ }^{8}$ Despite the fact that FSWs in India continues to be at most risk of acquiring and transmitting HIV there is a paucity of research about their perception of risk of being infected with HIV. ${ }^{1}$ The above features need to be studied in the context of the interventions.

This article is developed from the section of data from a doctorate thesis that investigated male condom use among FSWs of the red light area of Pune, Maharashtra. The objectives were an assessment of the risk perception, its association with condom use with different types of clients and the practice of HIV testing and the effect of knowledge about HIV on the perception of risk. The study would contribute to the literature in addition to the facilitation of planning and implementation of intervention strategies.

\section{Methods}

The study adopted mixed-method design. It was conducted in the red light area of Pune city in Maharashtra, India. Information about a number of brothels and FSWs was not available, which challenged the calculation of sample size. ${ }^{12}$ To resolve it, an approach specifically designed for such population was applied ${ }^{6}$ the red light area was mapped for a number of brothels and FSWs. It was found that the area has 2000 FSWs in 330 brothels. The list formed the sampling frame to calculate the sample size. An $\mathrm{n}=80$ was obtained after the application of a statistical formula recommended in a research manual for FSWs. ${ }^{13}$

A two-stage sampling method was applied. The selection of brothels with systematic random sampling followed by FSWs by convenience. Respondents' were requested for willingness and time to participate in

\footnotetext{
${ }^{*}$ Corresponding author. Symbiosis Institute of Health Sciences, India.

E-mail addresses: researchofficerscope1@siu.edu.in (M. Gore), prakash.nvp@manipal.edu (P. Narayanan), sanjay.juvekar@kemhrcvadu.org (S. Juvekar).
} 
the qualitative study during the interviews. Consequently, they were approached for in-depth interviews. An $n=20$ was achieved after the attainment of data saturation.

Ethics committee of Savitribai Phule Pune University approved the study. Written informed consent was obtained from respondents. FSWs able to write have signed the consent. Those not able to read and write gave written consent with an impartial witness (witness to the consent process). The literate colleague FSWs from the brothels have signed as witnesses.

Statistical Package for Social Science (SPSS) version 20 was used for analysis. Basics and inferential statistics were used for nominal and ordinal variables. Frequencies, percentages for univariate variables such as demographics, sex work variables were calculated. Cross tabulations with the application of chi-square tests, fishers' tests were used to determine the significance of associations between two variables.

Qualitative data analysis: All the interviews were conducted in Hindi as FSWs understand and speak the same language. They were translated in English. The inductive approach of qualitative analysis was used. A coding framework was developed, the patterns about risk perception, experiences about HIV testing, effect of native and sex work profile on risk perception were pooled under categories.

\section{Results}

\subsection{Characteristics of respondents}

Table 1 reflects the characteristics of respondents. More than a quarter was in the age range of 23-32 years. A majority i.e. (78.8\%) were illiterate. More than one fourth i.e. (33.3\%) FSWs were married, (25\%) were deserted, separated, or divorcees, a small percent i.e. (8.8\%), of respondents were widowed. These FSWs came from different states of the country such as (30\%) of FSWs were from West Bengal and Karnataka each, (22.5\%) were from Andhra Pradesh and remaining, (8\%) from Maharashtra and (6.3\%) included FSWs from Uttar Pradesh, North East and Madhya Pradesh.

Table 1

Distribution of respondents by socio demographic profile (quantitative $=80$, qualitative $=20$ ).

\begin{tabular}{|c|c|c|}
\hline \multirow[b]{2}{*}{ Variable } & \multicolumn{2}{|c|}{ Quantitative $(\mathrm{n}=80)$} \\
\hline & $\mathrm{n}$ & $\%$ \\
\hline \multicolumn{3}{|l|}{ Age in years } \\
\hline $18-22$ & 7 & 8.8 \\
\hline $23-27$ & 28 & 35 \\
\hline $28-32$ & 20 & 25 \\
\hline $33-37$ & 13 & 16.2 \\
\hline 38-42 & 9 & 11.2 \\
\hline Above 42 & 3 & 3.8 \\
\hline \multicolumn{3}{|l|}{ Literacy } \\
\hline Illiterate (cannot read and write) & 64 & 78.8 \\
\hline Literate (can read and write) & 16 & 20 \\
\hline \multicolumn{3}{|l|}{ Marital status } \\
\hline Unmarried & 15 & 18.8 \\
\hline Married & 27 & 33.3 \\
\hline Deserted/Separated/Divorcee & 20 & 25 \\
\hline Widow & 7 & 8.8 \\
\hline *Devdaasi & 11 & 13.8 \\
\hline \multicolumn{3}{|l|}{ Native } \\
\hline Maharashtra & 7 & 8.8 \\
\hline Nepal & 2 & 2.5 \\
\hline West Bengal & 24 & 30 \\
\hline Karnataka & 24 & 30 \\
\hline Andhra Pradesh & 18 & 22.5 \\
\hline Others & 5 & 6.3 \\
\hline Total & 80 & 100 \\
\hline
\end{tabular}

Table 2

Respondents' characteristics, knowledge about HIV/AIDS and perception of risk.

\begin{tabular}{llll}
\hline Perception of risk & Yes (\%) & No (\%) & Total \\
\cline { 2 - 4 } & $8(10)$ & $72(90)$ & $80(100)$ \\
\hline Profile & & & \\
Age in years & $4(11.8)$ & $40(88.2)$ & $44(100)$ \\
$\begin{array}{l}\text { 18-29 } \\
\text { M0-40 }\end{array}$ & $4(28.2)$ & $32(71.8)$ & $36(100)$ \\
Marital status & $4(14.8)$ & $23(85.2)$ & $27(100)$ \\
Married & $2(13.3)$ & $13(86.7)$ & $15(100)$ \\
Unmarried & $2(7.5)$ & $25(92.5)$ & $27(100)$ \\
Widow & $0(0)$ & $11(100)$ & $11(100)$ \\
Devdaasi & & & \\
Charges negotiated (INR) & $0(0)$ & $7(100)$ & $7(100)$ \\
Below Rs.100 & $7(11.3)$ & $55(88.7)$ & $62(100)$ \\
Rs.100-200 & $1(11.1)$ & $8(88.9)$ & $9(100)$ \\
Rs.201-300 & $0(0)$ & $2(100)$ & $2(100)$ \\
Above 300 & Knowledge about HIV/AIDS & $21(91.3 \%)$ & $23(100)$ \\
Low & $2(8.7 \%)$ & $51(73.5 \%)$ & $57(100)$ \\
High & $6(26.5 \%)$ & & \\
\hline
\end{tabular}

("Levels of knowledge were calculated based on the scores secured on the responses to the questions. To assess knowledge about HIV/AIDS six questions (awareness, source of information, misconceptions, knowledge about diagnosis and treatment) were asked. Each correct response was given score of one. The total score was summated. They were categorized into two levels: low and high).

* (The Devadasi tradition was widespread in South India. Known popularly as "temple dancers", the tradition involved the dedication of young girls for marriage to a god. Once these girls reached the age of maturity, they would become servants at local temples, often combining dancing and other artistic functions with sexual services to the priests and patrons of the temple. $)^{14}$

\subsection{FSWs risk perception of getting infected with HIV/AIDS and the effect} of socio demographic variable

Table 2 shows that the majority of FSWs (90\%) did not perceive the

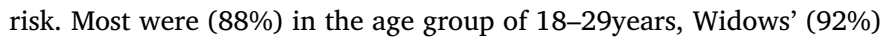
and all Devdaasis, did not perceive the risk. All FSWs charging less than 100 INR did not perceive the risk. A little less than three fourth (73\%) of respondents with a high level of knowledge about HIV did not perceive the risk.

3.3. Risk perception and condom use (with occasional new clients (OCNC), regular paying clients (RPC), and regular partners (RP))

Table 3 shows a high condom use (68\%) with occasional clients irrespective of non-risk perception. In contrast, non-risk perception reflected non-condom use of (55\%) and (91.8\%) with RPC and RP respectively.

\subsection{Risk perception and HIV testing}

Table 4 depicts that more than three fourth of respondents i.e. (84\%) were aware of HIV testing. Out of which majority (85\%) preferred the government's Integrated Counseling Testing Centers (ICTC)* for testing. With regard to the perception of risk and HIV testing, it was found that $(73 \%)$ not perceiving the risk underwent HIV testing.

*The Integrated Counseling \& Testing Center (ICTC) is a gate-way, a one-stop shop for a host of related services in HIV/AIDS prevention \& Care. Services provided in ICTCs: HIV Counseling - Pre-Test, PostTest. $^{16}$ 
Table 3

Perception of risk and its effect on condom use with different types of clients.

\begin{tabular}{llll}
\hline Risk perc. & \multicolumn{2}{l}{ Occasional client } & Total \\
\cline { 2 - 4 } & No & Yes & \\
\hline Yes & $2(25 \%)$ & $6(75 \%)$ & $8(100 \%)$ \\
No & $23(32 \%)$ & $49(68 \%)$ & $72(100 \%)$ \\
& Regular paying client & & \\
Yes & $4(50 \%)$ & $4(50 \%)$ & $8(100 \%)$ \\
No & $40(55.5 \%)$ & $32(44.5)$ & $72(100 \%)$ \\
Yes & FSWs with Regular partner & $6(100 \%)$ \\
No & $4(66.6 \%)$ & $2(33.4)$ & $49(100 \%)$
\end{tabular}

- Occasional new clients(OCNC)- visits occasionally but pays for sexual encounter.

- Regular paying partners-visit regularly and pays regularly.

- Regular partners-includes boyfriends, they may or may not cohabit with the FSWs but do not pay for the sexual encounter. ${ }^{15}$

Table 4

Awareness about HIV testing preferred place of testing, effect of risk perception on HIV testing.

\begin{tabular}{lll}
\hline Awareness about HIV testing & $\mathrm{n}$ & $\%$ \\
\hline Yes & 67 & 84 \\
No & 13 & 16 \\
Total & $\mathbf{8 0}$ & $\mathbf{1 0 0}$ \\
Preferred place for testing & & \\
ICTC & $\mathbf{5 7}$ & $\mathbf{8 5}$ \\
Private Hospital & $\mathbf{2}$ & $\mathbf{3}$ \\
Native & $\mathbf{1}$ & $\mathbf{1}$ \\
Don't know & $\mathbf{7}$ & $\mathbf{1 1}$ \\
Total & $\mathbf{6 7}$ & $\mathbf{1 0 0}$ \\
\end{tabular}

\begin{tabular}{|c|c|c|c|}
\hline \multirow[t]{2}{*}{ Perception of risk } & \multicolumn{3}{|c|}{ HIV testing } \\
\hline & Yes & No & Total \\
\hline Yes & $7(87.5)$ & $1(12.5)$ & $8(100)$ \\
\hline No & $53(73.6)$ & $19(26.4)$ & $72(100)$ \\
\hline
\end{tabular}

3.4.1. Findings from the qualitative study

3.4.1.1. Getting infected with HIV/AIDS - a remote threat. FSWs believed that getting infected with HIV is a distant worry. Their present concern was money with the entertainment of clients with or without condom use. The economic outlook prioritizes the effects of risky behavior. In these circumstances, perception of risk takes a back foot certainly. Other reasons for low-risk perceptions comprised faith-based thoughts, belief in destiny, a conviction in god controlling lives of humans.

The verbatim reveals FSWs' careless attitude and belief that destiny control's human lives.

FSW don't think much about the future, health is the last priority, and condom could break, tear, and slip what about such incidents and destiny would decide even if FSW is using condoms regularly she might get infected with the disease 45 years of FSW.

3.4.2. Nepalese FSWs' understood the risk, Devadasis' the traditional cult was far off from reality

Compare to other natives from the red light area, Nepalese FSWs understands the risk of unsafe sex. They ardently negotiate condom use or refuse the business otherwise. "Clients would come and go, important is our health, we have to keep ourself safe and healthy by refusing them who are unwilling to use condoms, I am totally aware of the risk" _-19 yrs Nepalese FSW.

Devadasis' being the traditional cult, inhabitants of the red light area for more than two decades perceive sex work as a normalize custom that is the underneath reason for non-risk perception. "My mother was a devadasi, I am too, life didn't offer me any choice than to become a sex worker, I don't know what is the risk, I don't think much. I am following her footsteps. The money earned would get counted ultimately". 32 year FSW (Devdaasi).

\subsubsection{No risk from my partner, I trust him completely}

FSWs aspire sustainability that leads to entertaining all types of clients; OCNC, RPC, RP. The majority keep regular partners and holds incredible trust that supersedes the risk. "My regular partner is like my husband, why should I fear about any infection even if he does not use a condom, I trust him completely. He does not wander looking for other girls". 38 yrs old FSW.

\subsubsection{Experiences of HIV testing-fear of seropositive test and perceived} consequences

The respondents showed a high awareness of testing and the places for it. They remembered campaigns organized for promotion (ICTC conducted special campaigns in the red light area). They knew testing after condom breakage incidences and during pregnancy. However, late receipt of reports demotivated follow up visits. One respondent reported that after the test came positive, she was successfully referred to a government hospital for the anti-retro viral treatment (ART). Some perceive stigma attached to the visits to the testing centers, so avoid repeated visits. A few believes that repeated testing is not essential if the test comes negative 2-3 times. "They have tested me in the brothel and my report came negative, why should I visit ICTC again after six months. Don't we have any other work than going for repeated testing"- 38 yr old FSW.

Positive result brings distress and tension a feeling of trauma and helplessness. A worry of getting out of the business as the insistence of condoms could reduce the number of clients and thus would impinge income. Till today they reminisce about the deaths of a positive colleague which creates shock and stress. FSWs under the wings of regular partners foresee strained relationships with them because of refusal of sex without condoms. A few shared that FSWs coerced into the trade fear most the seropositive result. "My colleagues would definitely discriminate me if they would come to know about the positive result" $-32 \mathrm{yr}$ old FSW.

\subsubsection{Denial of seropositive status}

One FSW denied her seropositive report, claiming that after being in the business for more than decade she can't be positive now as she does not reflect any symptoms. So, she did not trust the test result of ICTC and preferred to re test in her native instead. Further she added that FSWs are being targeted for spreading infection and are forced for testing.

\section{Discussion}

\subsection{Non-risk perception}

The finding of non-perception of risk was alike to the study results of Bali, Indonesia, and Mekong Delta, Vietnam., 17,18 In India, the National AIDS Control Organization (NACO) report documents risk perception in the range of $4 \%-77 \%$ in India and $27 \%-47 \%$ in the study area, higher than the present study's finding. ${ }^{6}$ Similarly, a survey in four states of southern India found that $40 \%$ FSWs perceived to be at high risk; more so in the state of Andhra Pradesh (56\%) and less in Maharashtra $(18 \%){ }^{1}{ }^{1}$ With the implementation of the HIV prevention interventions in the study area for more than two decades, this finding is significant.

The FSWs psyche about the perceived risk to be a remote threat, destiny controlling illness and health could be underneath rationale for non-risk perception. The finding supports anthropologists argument "[p]eople whose livelihood strategies expose them to a high risk of infection are, precisely because they are impoverished, less likely to 
take seriously... the threat of an infection that is fatal years from now". ${ }^{19}$ Found to be similar to other studies that revealed FSWs resolute beliefs in fatalism, predestination, and faith-based invulnerability to HIV infection. ${ }^{19}$ Interestingly application of the theory of cognitive dissonance expressed that FSWs' rationalized, defended their behavior a typical psychological response to hide worry, threat, and anxiety arising from the inconsistencies between beliefs and behaviors. They believed that one will not die of acquired immune deficiency syndrome if it is not fated. ${ }^{20,21}$ In another cross-sectional, qualitative study among FSWs in Blantyre, Malawi mixed perceptions were observed. Prayer and belief in God were reported to be protective from HIV acquisition while predestination or mere talking about HIV was perceived to result in vulnerability to infection. ${ }^{19}$

The majority of young FSWs attracts and entertains a number of clients; the financial gains are lucrative that blindfolds the perception of risk. So, focus on young FSWs in the interventions is necessary. The red light area constitutes a heterogeneous culture, as the FSWs are from different natives. Nepalese FSWs understood the risk correctly as compared to other natives. For Devdaasis, sex work is a normalize cult, that gets echoed in non-risk perception. These elements should be studied further.

Place of sex work and practice of unsafe sex was associated with high risk among FSWs of Vietnam and Barcelona. ${ }^{17,22}$ Considering India has various typologies of sex work of FSWs, place of sex work influencing risk needs to be explored with future research. ${ }^{23}$

Immense trust in an intimate relationship is the basis for no perception of risk and non-use of condoms supported by other studies. ${ }^{24}$ Comparatively, FSWs from Papua New Guinea recognizes high risk with occasional clients than in private sexual relationships. ${ }^{25}$ No association between charges negotiated and risk perception. A study reflects belief about soliciting high rates for unsafe sex is worth the risk. ${ }^{26}$

\subsection{Knowledge about condom use and risk perception}

Non perception of risk irrespective of high knowledge is in contrast to study among young population of Laos that revealed significant association between low risk perception and low levels of knowledge. ${ }^{24}$ In Sao Paulo, knowledge was independent of risk perception among postpartum women. ${ }^{25}$ A systemic review expounded association between knowledge about HIV/AIDS and risk perception, it discovered a scale from positive to no association and finally to negative. Further, the context in which risk is assessed is important and that need to be considered. ${ }^{27}$

\subsection{Risk perception and condom use}

Non-risk perception and non-condom use with RPC and RP is an important finding. Entertaining more clients because of low-risk perception was independently associated with inconsistent condom use in Kampala, Uganda. ${ }^{28}$ In Uganda, low risk perception and not infected with sexually transmitted diseases (STDs) are less likely to use condoms. ${ }^{29}$ In Lagos a survey shared low-risk perception in unsafe sex and low HIV knowledge as predictors of risky sexual behavior among men. Nonetheless in Mekong Delta study documented statistical significant association between perceived risk and inconsistent condom use. ${ }^{11}$ In India, prior inconsistent condom use with occasional clients was independently associated with present risk perception. ${ }^{1}$ The finding proves the association between perception of risk and condom use in FSWs but there are other predictors also.

\subsection{Risk perception and HIV testing}

The high percentage of HIV testing regardless of non-risk perception could be because of the promotional campaigns implemented that need to be studied further. The finding is similar to the Integrated Biological and Behavioral Assessment (IBBA) report, however, it's records of FSWs collecting the reports are in contrast with this study's finding. ${ }^{30}$ Conversely, in the state of Andhra Pradesh of India and in Mekong Delta, Vietnam, a low percentage of FSWs reported HIV testing, because of low-risk perception. ${ }^{9,31}$ In Mozambique and in Mekong Delta perceived risk was found to be the triggering factor for HIV testing, significantly associated in the univariate regression but not in multivariate regression. ${ }^{9,32}$ Similarly, in China, the high-risk perception was considered to be one of the factors for previous HIV testing. ${ }^{33}$ Respondents' preference for government centers for testing was similar to the finding of the study from AP. ${ }^{31}$ FSWs experiences of concern over the delay in receiving the test reports call for immediate action from authorities to seek solutions.

It was found that fear of the test coming positive refrain FSWs from visiting ICTC. A similar finding was found among university students in Thailand and South Africa. ${ }^{34,35}$ Those forced into sex work and exposed to unsafe sex feared the most. They associate emotions of distress, sadness, remember the deaths of colleagues and increased vulnerability to the seropositive result. This could be because of lack knowledge about HIV treatment. In Karnataka a study among FSWs discovered the fear of the psychological impact of the test in getting stigmatized for accessing HIV services. This was found to be a barrier in willingness for HIV testing. ${ }^{36}$

In Nacala, low uptake of the services was due to prior poor experiences with the ICTC centers. ${ }^{37} \mathrm{~A}$ review in Asia, Africa, and Latin America among different populations highlighted significant associations between HIV-related stigma and less use of ICTC, less willingness to disclose test results. ${ }^{38}$ In Andhra Pradesh the predictors of HIV testing were high risk behavior, young age, low income and no participation in a support group. ${ }^{29}$

\subsection{Limitations}

Gaining correct information about perceived risk among the population of brothel based FSWs is quite challenging. Risk assessment is a probabilistic concept, it indicates the probability that an action or activity would lead to an adverse outcome, which is difficult to explain. Individual's perception of risk is based on current knowledge and beliefs.

\section{Conclusion}

Mixed method design was successful in gaining insight into the research problem. Large percentage of FSWs had low risk perception irrespective of high knowledge; the reasons explored were concerns for survival overriding the risk, fatalistic belief, predestination and cognitive dissonance. The finding of non-risk perception leading to noncondom use need to be highlighted. Influence of age and native on perception of risk need to be studied further.

Interventions working to correct the perception of risk and translating it into a conduct becomes challenging because of FSWs inclination towards sex work for survival. A revamp of the Behavior Change Communication (BCC) campaign is recommended. The focus should be on benefit versus outcome attached with the risk, importance of selfworth that could motivate to avoid risky behavior. In the early phase of prevention, assessing readiness for change, motivation, risk sensitization is essential instead of focusing at the end of behavior change continuum of condom use only. It should deal fatalistic beliefs and help to sort cognitive dissonance.

Majority FSWs had undergone HIV testing irrespective of non-risk perception. Nonetheless, the experiences should be recommended for strategic changes in the functioning of the ICTCs. FSWs should be encouraged for six monthly testing and access of health care services in case of positive report. Though perception of risk is necessary to motivate preventive behavior it is not an independent influential factor. 


\section{Declaration of competing interest}

The authors have no competing interests to declare.

\section{References}

1. Jain AK, et al. Relationship between reported prior condom use and current selfperceived risk of acquiring HIV among mobile female sex workers in southern India'. BMC Public Health. 2011;11(Suppl 6):1471-2458 S5.

2. Ferrer R, Klein WM. Risk perceptions and health behavior. Curr Opin Psychol. 2015;5:85-89 Oct 1.

3. Rosenstock IM. Historical origins of the health belief model. Health Educ Behav. $1974 ; 2(4)$

4. Kumar, et al. Impact of targeted interventions on heterosexual transmission of HIV in India. BMC Public Health. 2011;11:549.

5. Wilson D. HIV programs for sex workers: lessons and challenges for developing and delivering programs. PLoS Med. 2015;12(6):e1001808.

6. Mamulwar M, et al. Differing HIV vulnerability among female sex workers in a high HIV burden Indian state. PLoS One. 2018;13(2):e0192130.

7. Ministry of Health and Family Welfare, Government of India. Department of AIDS Control, Annual Report. 2010-2011; 2010-2011.

8. Bruce E, et al. HIV knowledge, risk perception, and safer sex practices among female sex workers in Port Moresby, Papua New Guinea. Int J Women Health. 2011;3:53-61. https://doi.org/10.2147/IJWH.S14669.

9. Tran BX, Nguyen LT, Nguyen NP, Phan HTT. HIV voluntary testing and perceived risk among female sex workers in the Mekong Delta region of Vietnam. Glob Health Action. 2013;6. https://doi.org/10.3402/gha.v6i0.20690.

10. Ross, Markham C, Pham HTB. Health-seeking behaviour for sexually transmitted infections and HIV testing among female sex workers in Vietnam. AIDS Care. 2007;19(7):878-887. https://doi.org/10.1080/09540120601163078.

11. Fernandez OL, Molina-Azorin JF. The use of mixed methods research in the field of behavioral sciences. Qual Quantity. 2011:45(Number 6):1459.

12. Krishnan R, Wilson L. Rights and issues of people involved in prostitution in India-an analysis. Arts Educ Int Res J. 2017;4(Issue 2).

13. Lwanga Stephen Kaggwa, Lemeshow Stanley, World Health Organization. Sample Size Determination in Healthstudies : A Practical Manual. Geneva: World Health Organization; 1991 S. K. Lwanga and S. Lemeshow http://www.who.int/iris/ handle/10665/40062.

14. Neil JO, et al. Dhandha, dharma and disease: traditional sex work and HIV/AIDS in rural India. Soc Sci Med. 2004;59(4):851-860.

15. Ministry of Health and Family Welfare, National AIDS Control Organization, Government of India. Female sex workers and their clients. Natl Behav Surveill Surv. 2006 .

16. National AIDS Control Organization, Government of India. Integrated Counselling and Testing Centres. 2016; 2016www.naco.org.

17. Ford K, Wirawan DN, Reed BD, Muliawan P, Sutarga M. AIDS and STD knowledge, condom use and HIV/STD infection among female sex workers in Bali, Indonesia. Oct AIDS Care. 2000;12(5):52334.

18. Workie HM, Kassie TW, Hailegiyorgis TT. Knowledge, risk perception, and condom utilization pattern among female sex workers in Dire Dawa, Eastern Ethiopia 2016: a cross-sectional study. Pan Afr Med J. 2019 Apr 16;32(185).

19. Ramin B. Anthropology speaks to medicine : the case HIV/AIDS in Africa. McGill $J$
Med. 2007;10(2):127-132.

20. Twilzelimana D, Muula A S, HIV and AIDS risk perception among sex workers in semi-urban Blantyre, Malawi, Tanzania J Health Res Volume 17.

21. Ankomah A et al, HIV related risk perception among female sex workers of Nigeria, HIV/AIDS Auckland,3: 93-100.

22. Auli NC, Lancheros CM, Berenguera A, Pujol-Ribera E. Risk perception of sexually transmitted infections and HIV in Nigerian commercial sex workers in Barcelona: a qualitative Study. Qual Res. 2015;5(6).

23. BuzduganR, Halli SS, Cowan FM. The female sex work typology in India in the context of HIV/AIDS. Jun Trop Med Int Health. 2009;14(6):673-687. https://doi.org/ 10.1111/j.1365-3156.2009.02278.x Epub 2009.

24. Bailey AE, Figueroa JP. Agency, lapse in condom use and relationship intimacy among female sex workers in Jamaica. May Cult Health Sci. 2018;20(5):531-544. https://doi.org/10.1080/13691058.2017.1360944 Epub 2017 Sep. 1.

25. Sychareun V, Thomsen S, Chaleunvong K, Faxelid E. Risk perceptions of STIs/HIV and sexual risk behaviours among sexually experienced adolescents in the Northern part of Lao PDR. Bio Med Central. 2013;13:1126. https://doi.org/10.1186/14712458-13-1126.

26. Praça NS, Latorre M, Hearst M. Factors associated with HIV risk perception among hospital postpartum women. RevistadeSaudePublica. 2003;37(5).

27. Kabwama S, Berg-Beckhoff G. The association between HIV/AIDS-related knowledge and perception of risk for infection: a systematic review. Perspect Public Health. 2015; XX(X 1).

28. Innocent N M, James M, Fred A E, Jonathan O, Natal A, Risk perception and condom use in Uganda, Afr Popul Stud, vol. 18.

29. Bukenya J, Vandepitte J, Kwikiriza M, Grosskurth H. Condom use among female sex workers in Uganda. AIDS Care : Psychol Socio-med Aspect AIDS/HIV. 2013;25(6):767-774. https://doi.org/10.1080/09540121.2012.748863.

30. NACO, ICMR, Ministry of Health and Family Welfare. Integrated Biological Behavioral Surveillance (IBBA). 2010; 2010www.naco.gov.

31. Dandona, et al. HIV testing among female sex workers in Andhra Pradesh, India AIDS. AIDS. 2005;19(17):2033-2036.

32. Langa J, et al. HIV Risk Perception and Behavior Among Sex Workers in Three Major Urban Centers of Mozambique. 2014; 2014https://doi.org/10.1371/journal.pone. 0094838.

33. XU J, et al. Factors associated with HIV testing history and HIV-test result follow-up among female sex workers in two cities in Yunnan, China. Sex Trans Dis. Feb. 2011;38(2):89-95.

34. Churcher S. Stigma related to HIV and AIDS as a barrier to accessing health care in Thailand: a review of recent literature WHO South-East Asia. J Public Health. 2013;2(1)

35. Meiberg A, Bos A E, Onya H E, Schaalma H P, FEAR OF Stigmatization as barrier to voluntary HIV counselling and Testing in South Africa,East Afr J Public Health Volume 5 Number 2.

36. Beattie T, et al. Personal, interpersonal and structural challenges to accessing HIV testing, treatment and care services among female sex workers, men who have sex with men and transgenders in Karnataka state. South India J Epidemiol Community Health. 2012;66:ii42eii48. https://doi.org/10.1136/jech-2011-200475.

37. Ministry of Transport and Communications. The Preparatory Survey on Nacala Port Development Project in the Republic of Mozambiue, Final Summary Report. 2011; 2011.

38. Pulerwitz J, et al. Reducing HIV-Related Stigma: Lessons Learned from Horizon Research and Programs Public Health Reports. vol. 125. March-April 2010; March-April 2010 